\title{
Genres and Multilingual Contexts: The Translational Culture of Nineteenth-Century Calcutta ${ }^{1}$
}

ChANDRANi ChATTERJEE

\begin{abstract}
Nineteenth-century Calcutta has been widely researched to understand its role in the making of a 'modern' India. However, the 'translational' culture of this period has not received enough attention. The present article traces what it terms Calcutta's 'translational culture' by examining a palimpsest of languages and genres through the mediating role of translation. Nineteenth-century was a time when several languages were competing for space in the making of modern Bengali prose. Most of the writers of the time were negotiating a plural and multilingual domain and experimenting with new styles of prose and poetry writing.

Two such examples can be seen in the works of Michael Madhusudan Dutt (1824 - 1873), and Kaliprassana Singha (1841 -1870). These writers were instrumental in the making of new genres and were negotiating multiple languages and linguistic registers that included - Sanskrit, Bengali with its different elite and colloquial registers, English, and several European languages and literatures. In juxtaposing Dutt and Singha, the present article attempts to point towards a parallel history of the nineteenth-century Calcutta traced through moments of transactions, translations, and negotiations among languages, ideas, and world views. Languages and literary genres in this case become a testimony to the rich texture of social and cultural negotiations that went into the making of

${ }^{1}$ I am grateful to Dr. Hephzibah Israel for her generous comments and suggestions on an earlier version of this article. I am also grateful to the reviewers of Translation Today who read the article and provided important suggestions.
\end{abstract}


the modernist Bengali prose and indicative of its palimpsestic and translational nature.

Keywords: Translation, Translational, Genre, Multilingual, Palimpsest, Calcutta.

\section{Introduction: Genre, Translation, and Multiple Language Registers}

In this article, I attempt to rethink the use of genre as a form of translation and how this intersects with the prevalent multilingualism of the nineteenth-century Calcutta. This will also help us analyse how genre interacts with multiple languages, in the works of the writers of the time, presenting a more complex picture of translation overall. In negotiating a multilingual domain, the writers of the period were not only participating in the ongoing debate of linguistic hierarchies but in preferring one linguistic register or a mixture of registers for their genres they were actively contributing to the discourses of the times. In many cases this led to curious negotiations of language registers, the colloquial, vulgar, and everyday merging with the elite and standardized as in Kaliprassana Singha (1841-1870) or in Tekchand Thakur's (1814-1883) writings. In other cases, the linguistic registers facilitated the emergence of new genres be it the refined elite Bengali of Madhusudan Dutt's (1824-1873) epic and sonnets or the irreverent tone of the colloquial in Singha's sketches. It is with this intent that the present article juxtaposes two literary figures of nineteenth-century Calcutta - Kaliprassana Sinha and Michael Madhusudan Dutt. ${ }^{2}$ They are looked upon not merely as creative writers but as translators who were

${ }^{2}$ While the fashioning of European forms in nineteenth-century Bengali literature is a well-established fact, the present article hopes to extend that analyses to show how genre intersects with the use and presence of multiple languages and the many registers within the same language. 
Genres and Multilingual Contexts: The Translational Culture...

negotiating multiple languages in genre innovations in a prevalent 'translational' culture.

I use the word 'translational' in the sense that recent scholarship in the field of Translation Studies has been using the term. I am particularly referring to Edwin Gentzler's recent work on translation and rewriting where he alerts us to the need to acknowledge this larger and more prominent presence of translation in our lives:

[...] I argue that rather than thinking about translation as a somewhat process of ferrying ideas across borders, we instead think about translation as one of the most important processes that can lead to revitalizing culture, a proactive force that continually introduces new ideas, forms or expressions, and pathways for change (Gentzler 2017: 8).

Translational cultures are palimpsestic in nature - a process that involves different linguistic registers for certain, but also involves creative interferences like the ones we will be discussing in this article. The multilingual context and the different linguistic, literary, and cultural translations in the nineteenth century Calcutta make it such an apt illustration of a translational culture.

In her 2012 book, Cities in Translation: Intersections of Language and Memory, Sherry Simon discusses four cities, Calcutta, Trieste, Barcelona, and Montreal as examples of translational cities. Locating the special character of these cities "in the presence of two historically rooted language communities who feel a sense of entitlement to the same territory", Simon called these "dual cities" (Simon 2012: 3).

These cities are not bilingual: they are translational. This term more adequately accounts for the range of relations that sustain the urban imagination - relations that include indifference and 
negation as well as engagement and creative interference. Movement across languages is marked by the special intensity that comes from a shared history, common territory, and the situation of contending rights. Successful negotiation across these commonalities and differences becomes the very condition of civic coexistence. But at the same time, translations are rarely neutral events in a placid field of encounter, rather they are events that sustain or transform social and literary interrelations" (Simon 2012: 3).

Nineteenth-century Calcutta was undoubtedly a translational city juggling with linguistic and cultural registers for creative expression. This was facilitated by the rather fluid understanding of the concept of translation and sheer proliferation of translated texts in this period. In his seminal work, Kalantare Bangla Gadya: ouponibeshik amale gadyer rupantar (Transformation of Bengali Prose During Colonial Rule, 1992) Golam Murshid has illustrated the ways in which colonial rule transformed cultural practices and led to a Sanskritization of the prevalent practices of both the spoken and written. Murshid cites the case of several translators, primarily British officials, who were engaged in the activity of translating grammar books and setting the path towards a standardization of the Bengali language. Murshid's work is important in drawing our attention to the role of translations in the making of Bengali prose. While Murshid looks at conventional translations, that is, translations between languages, this article humbly proposes that much more was happening at the level of exchange and interaction among different writers and the socio-cultural circumstances, which was reflected in the introduction of several new genres of the time making the multilingual history further complex. ${ }^{3}$ These

${ }^{3}$ Tejwaswini Niranjana's very important study, Siting Translation: History, Post-Structuralism and the Colonial Context (1992) had viewed 
Genres and Multilingual Contexts: The Translational Culture...

new genres can be studied as a form of translation. While different language registers were competing for space in the nineteenth century, there was a parallel dialogue among creative writers on the choice of genre and the linguistic registers suited to particular genres. The multiple levels at which authors and creative artists were negotiating not only language and texts as a part of the new curriculum and education system, but a whole new world of ideas and concepts paving the way for the experimentation in new genres can be looked upon as a site for exploring the 'translational' in the nineteenth century. ${ }^{4}$

The word 'translation' was used both literally and conceptually and in varied ways. For example, rupantar (lit. change of form); bhavanuvad (lit. translation of ideas) were as much a part of the vocabulary that included bhashantar (lit. linguistic translation), anuvad (lit. coming after or following speech), and tarzama (the Perso-Arabic term for translation) among others were often used interchangeably. This fluidity of concepts and the possibility of shifting from one notion to the other while referring to translation are perhaps indicative of a plurality that was available to the writers of the time. This is also illustrated in the many ways in which the idea of translation was in circulation and in the making, in turn fashioning an entire generation of learners and practitioners of

translation as a political act. Urging readers to think of translation as a site of transformation and contestation, Niranjana's work is an important intervention in the rethinking of translation from the colonial and post-colonial perspective.

${ }^{4}$ Path-breaking scholarly work on the beginnings of English education in India and its socio-cultural impact is Gauri Viswanathan's Masks of Conquest: Literary Study and the British Rule in India (1989). Informed by Viswanathan's work, the present article proposes to discuss the role of multilingualism and genres. Thinking of genre as a mode of translation the article hopes to revisit the nineteenth century through select readings of writers and the genres that they introduced. 
cultures. One is reminded of the early days of print culture in Calcutta and the innumerable titles that were churned out from the local presses in this regard. ${ }^{5}$ Many of these titles were either direct translations of some English work or were inspired by English writers. There were also adaptations from well-known English novels or plays and all of these were generally looked upon as independent works in their own right. The closest one came to acknowledging sources in these formative days of print culture was by citing works as being 'inspired' by some work or writer. ${ }^{6}$ The ideas of translation, adaptation, and inspiration easily flowed into each other and there was fluidity in the ways in which these concepts were used most often interchangeably. A study of the title pages of these early printed books reveals the many linguistic registers that were visibly available to the reader. Often, Bengali and English would be used together on the title page. At times, there would be English quotations from well-known English writers on the title page along with the author's name and the publication details.

The role of the colonisers cannot be overlooked here. As Swapan Chakravorty alerts us, the numerous translations produced by the East India Company, Fort William College, the Serampore Baptists, and the various societies for promoting religious and secular learning set up by both the

${ }^{5}$ Anindita Ghosh's, Power in Print: Popular Publishing and the Politics of Language and Culture in a Colonial Society, 1778-1905 and Priya Joshi's, In Another Country: Colonialism, Culture and the Novel in India have been instrumental in initiating discussions around print history and the ensuing print culture in the colonial era. Ghosh's work also throws light on the variety of genres of the period and the many linguistic registers of the time.

${ }^{6}$ See Checklist of Nineteenth-Century Bengali translations of European Texts (1800-1900) prepared by the Department of English, Jadavpur University, Kolkata, 1996. 
Genres and Multilingual Contexts: The Translational Culture...

British and Bengalis facilitated this rather fluid, translational space.

Translations of alien themes and narratives necessarily produced a defamiliarized hybrid prose. It is for this reason that the Vernacular Literature Society [...] decided to make haste slowly. The introduction of its first commission, Harachandra Dutt's Lord Clive (1852), a version of Macaulay's biography, declared that 'the object of the association is distinctly stated to be not only to translate but to adapt English authors into Bengali (Chakravorty 2004: 208).

This translational space continued for the most part of the nineteenth century. The journals and periodicals of the times have some interesting examples to provide. The first Englishlanguage newspaper from Bengal was titled The Bengal Hurkaru and Chronicle. The use of the Persian word Hurkaru or messenger indicates the kind of linguistic and conceptual mix in literature produced by the British, which affected both colonised, and coloniser! $!^{7}$

The writers of the time experimented with the many aspects of genre and translation. To study this phenomenon, I will discuss two contemporaneous writers - Michael Madhusudan Dutt (1824 - 1873) and Kaliprassana Singha (1841 -1870). I will look upon these literary figures not merely as individual artists but as negotiators and interlocutors in the larger discourse of the remaking of the nineteenth-century Bengali language and

7 In another instance, as Swapan Chakravorty illustrates, "The first Bengali periodical run by Muslims, for example, Samachar Sabharajendra, was a Bengali-Persian bilingual when it started life in 1831. Fifteen years later, it was setting its pages in five columns, Bengali and Urdu on either fringe, with English in the middle flanked by Persian and Hindi. This illustrates the curious co-existence of interlingual translations, a rare typographic image and also bears witness to the unstable identity of Muslims in Bengal under Hindu cultural dominance and British political rule." (2004, 208-209) 
literature. They were instrumental in the making of new genres and were negotiating several linguistic domains. These negotiations took different trajectories - sometimes in literal borrowings from linguistic registers, at other times borrowing styles of writing available in genres in other languages, in some other cases the intermixing of linguistic registers to suit the content and the form of writing. In fact, even when not dealing with multilingual texts and translations, early printed prose texts and sometimes the same text tended to display a wide variety of registers, dialects, and stylistic differentiation.

The connection between the prevalent multilingual context and the experimentation through genres requires closer scrutiny. The point of contestation in the nineteenth century was not only the different registers of the Bengali language but also the distinction between the varieties of spoken and written languages. While the purification drive was to rid Bengali of its Persian and Arabic loans and to standardize the written word, the world of the spoken remained a largely loose field wherein the everydayness of the colloquial one could feel a deep hybridisation and traces of earlier borrowings. These multiple linguistic registers become the subject of Kaliprassana Singha's fictional world in Hutom Pyanchar Naksha (lit. The Observant $O w l 1862$ ). This work is particularly significant for its use of colloquial Bengali, spoken in the city, which would gradually be replaced by a more formal and standardized authoritative Bengali prose in the last decades of the nineteenth century. Bankim Chandra Chatterjee would later criticize the prose and style of Singha's fiction calling it 'inauthentic' Bengali. The Bengali of Singha's fictional world was suited to the genre of the 'naksha' or the 'sketch' perhaps modelled on Dickens' Sketches by Boz. The nineteenth-century witnessed a significant rise in such social portrayals, often veering on the satirical. The experimentations with Bengali prose achieved new heights in this genre. Kaliprassana Singha was one of 
Genres and Multilingual Contexts: The Translational Culture...

those who helped in refashioning the style of Bengali prose writing.

Michael Madhusudan Dutt's experimentations with the Bengali language were modelled on following the European literary models. Being an avid reader of the European tradition he was translating what he was reading into his Bengali styles, concepts, and ideas. As discussed below, this led him to introduce the blank verse in Bengali poetry and the sonnet in Bengali. This was an age of the old and the new; the different official languages, Persian, Sanskrit, Bengali, English coexisted; religions like Christianity, Brahmoism, Hinduism, and Islam were jostling for space and prominence; an age of reforms and proposed changes like widow remarriage, intercaste marriage, sea-voyages, inter-dining were already creating upheaval and tension in the established pattern of the joint family which was looked upon as a marker of tradition. Both Singha and Dutt's writings provide interesting entry points to the fields of linguistic and cultural conversations and contestations in nineteenth-century Calcutta, a complex lingual history and a rich translational fabric waiting to be re-read and negotiated.

\section{Hutom Pyanchar Naksha (1862): Translating Everyday Language}

Hutom Pyanchar Naksha (henceforth Hutom) may be credited as the first Bengali work in prose that successfully experimented with the use of the colloquial and the everyday speech in writing. Though criticised by Bankim Chandra Chatterjee, for its gross colloquiality, Hutom did influence Bengali prose writing in a fundamental way and the work surpassed its age and time because Singha set a trend of using the everyday speech in writing and of painting as clear and distinct a portrait as possible of the times in which he was 
living. The Calcutta Review, in 1871, published the following about the author of Hutom:

"[...]. In early youth he made several translations from the Sanskrit, and in particular he is the author of a translation of the Mahabharata, which may be regarded as the greatest literary work of his age. But it is not as a translator that he is known and familiar to almost every Bengali, but as the author of Hutam Pyanchaa, a collection of sketches of city-life, something, after the manner of Dickens' Sketches by Boz, in which the follies and peculiarities of all classes, and not seldom of men actually living, are described in racy vigorous language, not seldom disfigured by obscenity." 8

What is interesting in the above comment are two facts about Singha's literary career. Singha, we are told, translated the Mahabharata from Sanskrit. We are also told that his claim to fame lay in his sketches, which were written in colloquial Bengali following Dickens' Sketches by Boz. ${ }^{9}$ This indicates the translational fabric of the times in which Singha and his contemporaries were reading and writing. Competence in Sanskrit, which led to the mammoth task of translating the Mahabharata, needs to be juxtaposed with an equal familiarity with and knowledge of the English literary tradition that Hotum was modelled on. Hutom becomes the melting pot of a society that was experiencing rapid cultural transformation

${ }^{8}$ Cited in Hutom Pyanchar Naksha by Kaliprassana Sinha, edited by Sri Bajendranath Bandyopadhyay and Sajanikanta Das, Calcutta: Bangiya Sahitya Parishat, p 8-9.

${ }^{9}$ Whether 'naksha' as a form had a precedent in the Persian literature is not known. What is referred to as Mussalmani-Bengali writing in the nineteenth century, often a mixture of Persian and Urdu, does not mention any practice in the 'naksha' form. However, MussalmaniBengali writing is often referred to as a genre in itself (as illustrated in Anindita Ghosh's Power in Print) and did produce a substantial body of writing in this period. 
Genres and Multilingual Contexts: The Translational Culture...

more generally, and relevant specifically to this article, experiencing a rich array of languages and literary genres. Singha's sketches become the first instance of a language debate that would lead to similar discussions both in the elite and popular print literature of the times and in later years. A closer look at Hutom would help understand the highly layered nature of Singha's work and the constant negotiations that were at work in the age that Hutom describes. In fact, the tone is set at the very beginning of Hutom,

The Bengali language has now become the refuge of many writers like us who dabble in literature. Just as idle children knock up dolls of sorts out of abandoned dough or lumps of clay, many scribblers now rig up fanciful things out of the uncared for Bengali language. If the Bengali language had some worthy heir to look after it, it wouldn't have been harried by schoolboys and dunces like us. Many authors would have been strung up by now, and many thrown into jail. This gave us the opportunity to take possession of the Bengali language. But we found nothing new to engage ourselves in. The situation was such that everyone dabbled in everything. We, therefore, decided to begin writing sketches like these (The Observant Owl, translated by Swarup Roy 2008: xviii).

The above passage locates Hutom in an already ongoing linguistic battle. The battle is about the Bengali language, which is 'uncared for' and does not have a 'worthy heir'. There is an obvious tone of self-mockery in ridiculing the current practitioners of the Bengali language as 'schoolboys and dunces.' However, there is also a triumphant note at being able to take possession of the Bengali language because it lacks able heirs. There is an indication of the disciplining of the language (probably a remark on the prevalent cleansing drive) where recalcitrant authors would be 'jailed'. What is also interesting is that the connection between the colloquial 
Bengali register and the genre of the sketches is clearly drawn out. Had the purists or the 'worthy heirs' taken over, there would not have been the possibility of a genre like the sketches which draws heavily on the everyday cultural and linguistic domain as its medium. Just as the who's who of his times were targeted and described in the pages with pungent humour, so does the anonymous common man find a place in these descriptions. It is through these that the pulse of the city life gets best translated in the pages of Hutom. The final section on the railways deserves special mention here. Here the early days of the introduction of the railways are referred to and a narrative is created around the dismantling of the old system of caste hierarchies. The railways made it possible for people across caste boundaries to travel in this new mode of transport. This is an important moment in the advent of modernity - a transition that unsettled prevalent hierarchies and customs. The effortless narration and the experimentation with a variety of Bengali spoken in the Calcutta of the times, a popular urban spoken language that virtually disappeared from the printed pages of Bengali literature with the establishment of more standard prose later in the nineteenth century, makes Singha's work so vibrant a document of its times.

In Singha, linguistic changes become a representation of a change in lifestyle and he leaves no stone unturned in attacking the profligacy and licentiousness of a class of men who in their imitative eagerness of emulating an English way of life had transformed every aspect of their life and living - the drawing room being an apt witness to this. Describing babus in their western-styled drawing rooms, Singha writes,

There are two groups of anglicized babus in the city now. The members of one group are like cowdung busts of well-bred sahibs, and the members of the other are crappy imitations of feringhees! The first group follows the English style in 
everything: having at-homes around tables and chairs, drinking tea from cups, smoking cigars, keeping water in jugs, serving brandy from decanters, covering glass tumblers with beautifully decorated lids etc. [...] They dine at tables, shit in commodes, and wipe their butts with paper! (The Observant Owl, translated Swarup Roy: 15-16).

It is amidst such cultural and linguistic discourse that the making of modern Bengali prose can be understood. There was a contestation around the use of language, the kind of language that became a marker of a particular literary and aesthetic taste - also thereby creating a dichotomy between the acceptable and the non-acceptable in language - a divide between the elite and the popular, the standard and the non-standardised versions. This was further augmented by the onslaught of the print phenomena and the associated ideas of standardization that print necessitated. Print unleashed a variety of readerships and a diversity in the kind of material published. Eventually, the print came under the strict surveillance of the colonial rulers and the debate around obscenity came to the forefront. It is in this trajectory of events that the language debate can be located. ${ }^{10}$

At a time when the general language of prose narration in Bengali literature was heavily Sanskritised, Singha's use of the colloquial and everyday varieties of Bengali used in the rapidly transforming urban space of Calcutta was a remarkable intervention. The repeated use of bawdy quips and scatological humour offended genteel sensibilities and was attacked as obscene and vulgar. Through a gradual process of disciplining the presence of the colloquial, and the spoken word would

${ }^{10}$ See Anindita Ghosh, Power in Print: Popular Publishing and the Politics of Language and Culture in a Colonial Society, 1778-1905, New York: Oxford University Press, 2006 
eventually be translated into the more acceptable forms of standardized Bengali prose.

Many well-known journals and dailies of the time were engaged in similar debates. Notions of taste, public decency and the like were concerns that surfaced time and again in these debates. In their zeal to discipline the Bengali language from within, the elites not only created a schism that would henceforth be regarded as the determinant of the elite vis-a-vis popular culture; but also criticized and derided writers from within, who did not fit into this classification. So, a text like Hutom, obviously came under scrutiny.

Kaliprassana Singha's colloquial style and satiric sketches were classified as a departure from the standards of taste set by the elites of the times. Hutom was not the only text nor was Sinha the only writer who seemed to have departed from the conventions that determined a chaste and standard literary prose of the nineteenth century. Writers like Bhabanicharan Bandyopadhyay (1787-1848) and Peary Chand Mitra (18141883) also came under scrutiny for similar reasons - for furthering the cause of a loose style of colloquial Bengali, which amounted to the vulgar.

Peary Chand Mitra and Radhanath Sikdar (1813 -1870) started a literary magazine called Mashik Patrika in the year 1855 to counter the growing Sanskritization of the Bengali language by the likes of Ishwarchandra Vidyasagar among others. In the preface, they announced that the magazine was particularly catering to the common people and women and would follow a language of day-to-day conversation. They further suggested that if scholars chose to read it, they could, though they were certainly not the intended audience. It was in the Mashik Patrika that Peary Chand Mitra's Alaler Gharer Dulal [1857, lit. The Spoilt Boy] was serialized which announced a fundamental change in Bengali prose style in using colloquial 
everyday spoken language in criticising a rapidly transforming society. The language used here would be henceforth known as 'alali bhasha' (lit. the language used in Alaler Gharer Dulal) and would be followed and excelled by the likes of Kaliprassanna Singha.

It is amidst this debate that a distinct, colloquial, and popular print phenomenon thrived in Calcutta churning out a variety of genres including sketches, satires, ephemeral literature, chapbooks, social farces, and novels thwarting the process of sanitization, cleansing, and disciplining. What is noteworthy is that many members of the elite literati like Kaliprassana Singha and Peary Chand Mitra were as much practitioners of this style and kind of writing. In its attempts to keep the elite and the popular distinct, there were several overlaps and it would not be incorrect to suggest that the modern Bengali prose grew, developed, and matured through these several stages of negotiations and transactions that cannot perhaps all be grasped in a discourse that talks in terms of colonial hegemony. This hegemony itself was enshrined in the polemics of the times that was shaping the sensibility of nineteenth-century Bengali literature that would not have been what it became without its alter ego - the colloquial, nonstandardised, popular writings that were also produced in this time. It is perhaps enabling to rethink this period in literary and cultural history through the connection between multilingualism and translation. It may be argued that this connection was instrumental in the formation of new genres, in fact, that these genres are a form of translation. Modern Bengali prose may thus be seen as a consequence of these many translational acts exhibited in the literary imagination of the times. In fact, the genre of the novel may be regarded as a culmination of these many translational acts. 


\section{Michael Madhusudan Dutt: Translating Linguistic and Literary Traditions}

While Kaliprassana Singha's Hutom Pyanchar Naksha provided a glimpse into the translational aspect of genres in nineteenth-century Bengali prose literature, Madhusudan Dutt's life and literary oeuvre help us configure some more connections between multilingualism, translation, and genre. A first-generation learner of the English language who practiced in English, nurturing a dream to be a famous poet in English and then returning to his native Bengali. Dutt used the elite and Sanskritised variety of Bengali both for his first blank verse epic and sonnets. However, what is interesting and rather well established is that even while writing in Bengali, Dutt was constantly referring back to the European models as sources that he was emulating. This juxtaposition of a European and English literary tradition alongside a Bengali literary tradition and a translation of the former into the latter are clearly visible in Dutt's creative experimentations. These translations were simultaneously at the linguistic, stylistic, generic, and ideological levels that created a dense palimpsest of sorts. ${ }^{11}$

Madhusudan Dutt's life is exemplary of nineteenth-century Calcutta in several ways. A first-generation learner of the English language, Dutt like many of his contemporaries was deeply enamoured of the language and its literature, which was a significant part of the curriculum that was responsible for creating an image of the English life and culture in him. He was a true polyglot, with a keen interest in languages, and in several of his letters, there is repeated mention of his newly

${ }^{11}$ Michael Madhusudan Dutt is a much discussed writer in the Bengali literary world. Several scholarly studies are available which discuss Dutt's literary and cultural contribution to the Bengal Renaissance. The present article attempts to extend such already available research to point towards the dimension of multilingual contexts in Dutt's writings. 
Genres and Multilingual Contexts: The Translational Culture...

honed linguistic skills. In a letter written to Ishwarchandra Vidyasagar, dated $2^{\text {nd }}$ June 1864, Dutt writes seeking help about increasing debt but mentions his newly acquired linguistic skills

Though I have been very unhappy and full of anxiety here, I have very nearly mastered French. I speak it well and write it better. I have also commenced Italian and mean to add German to my stock of languages, - if not Spanish and Portuguese before I leave Europe. (Collected Works of Michael Madhusudan Dutt, $5^{\text {th }}$ edition, 1999)

It is this zeal for learning languages and traversing different linguistic and literary zones that gave Dutt his writing models for creative expression. In Dutt's case, English literature left such a strong mark that he wanted to be famous as an English poet in England. This dream and the struggles that accompanied in moving towards this dream is a well-known episode and have been recorded and documented by scholars who have studied Dutt's life. ${ }^{12}$ Here, however, my concern is to understand Dutt's fascination with languages and literatures - Dutt the polyglot who traversed linguistic and cultural divides in his creations. Dutt's writings bear testimony to the layered nature of literary and cultural transactions that he was engaged in.

Dutt was well versed in Greek, Latin, French, Italian, Bengali, English, and Sanskrit. However, more than being a mere user of these languages, Dutt's creative oeuvre is replete with instances of very detailed negotiations and intermingling that would seldom qualify as mere imitation. It would be an impossible task to even attempt a survey of Dutt's writing career given the prolific nature of his literary productions.

12 Golam Murshid's biography of Madhusudan Dutt is a fascinating scholarly account of the poet's life. For more details see Ashar Chalane Vuli, Kolkata: Ananda Publishers, 1995 
What I will nonetheless attempt here is to illustrate how the transitions in the different phases of his writing career can be seen as indicative of his being a polyglot translating across languages and literatures - for in a single work like the Meghnad Badh Kavya (The Slaying of Meghnad) one can perceive how different cultural and literary traditions have been translated to create a blank verse epic for the first time in Bengali literature. Dutt was well versed in the western classical tradition as he was in the English tradition of the likes of Milton. He also knew the Indian epics like the Mahabharata and the Ramayana. In Meghnad Badh Kavya one sees the coming together of all these several traditions. This trait is not limited to the epic genre alone, but can be seen in his other works as well, be it the sonnets or a poem like The Captive Ladie.

While many nineteenth-century Bengali writers and artists were following a similar model and practicing and participating in a translational culture that is more than evident in the dense and nuanced textures of their writing, Dutt best affords an example of the highly textured nature of the nineteenth century and its 'translational' culture. Here, I would like to urge us to think of translation as 'cultural traffic', essentially a two-way process of exchange and agential participation that goes into the making of cultural artefacts.

Dutt's sonnets are a good example of such cultural traffic. Dutt wrote his sonnets towards the end of his writing career. So, it would be more appropriate to understand the sonnets as his mature work. Of the many forms introduced into Bengali literature in the nineteenth century, the sonnet holds a unique position. There was nothing like the sonnet in the Bengali literary imagination till then - both in terms of the formal features and the scope that it afforded to its practitioners. Michael Madhusudan Dutt was the first to introduce the sonnet 
into Bengali literature. In one of his letters, addressed to his friend Raj Narayan Basu, Dutt notes, "I want to introduce the sonnet into our language...if cultivated by men of genius; our sonnet would in time rival the Italian." Dutt published a collection of one hundred and two sonnets called Chaturdashpadi Kavitavali (1866), written during his stay in France.

In the second poem of the anthology, the poet relates the brief history of the sonnet and its introduction into Bengali literature. Dutt wrote a sonnet in Bengali, tracing the history of a new genre that was being introduced into Indian poetry from European literature. He reminds the reader of the Italian poet Francesco Petrarch, who found this little gem in the mine of poetry and dedicated it to the temple of the Muse. The Goddess accepted the gift and rewarded the poet graciously. In a similar fashion, Dutt offers the gem, which he considers a suitable gift to ancient Bengali poets and poetry. What is interesting in Dutt's use of the sonnet is his playful creativity translating the sonnet, primarily the European and English models, to the context of nineteenth-century colonial Calcutta. The sonnet becomes for Dutt a means to lament the time he as a poet had desired to become famous in English. The Bengali sonnet for Dutt becomes a mouthpiece for advertising the rich literary and cultural heritage of his first language that he had overlooked early in his writing career. What makes this process even more fascinating is the fact that the sonnet, a European form becomes the site for announcing this shift - a shift that would be symptomatic of many writers of the nineteenth century. The sonnet did not appear to Dutt, to be a fixed European genre for all time, but as one that could be appropriated and translated to a different social and cultural milieu. The third sonnet, for example, is a lament, where the poet realizing the potentialities of his first language, condemns his seeking of the English language for practicing poetry. This 
sonnet ends with the advice of the Muse and the poet's return to his 'mother tongue'. This initial experimentation with the colonizer's language and then a return to one's first language is symptomatic of many writers who were writing around this time. ${ }^{13}$ Michael Madhusudan Dutt was one among his peers to participate and translate this ongoing discourse.

It is important perhaps to understand at this point, the process and moment of appropriation of a particular genre. What the recipient culture considers worth imitating needs to be taken into consideration in this regard. In the case of Michael Madhusudan Dutt, the European sonnet form, not only provided a model, but also the scope for innovation and experimentation. Several noted genre theorists have commented on the permeability of generic boundaries and the ways in which genres transform and translate themselves across cultural borders. In Michael Madhusudan Dutt's experimentation with the sonnet, his need to deviate from his precedents also reveals a new awareness of form and textuality - an awareness that goes into the making of the sonnet in Bengali, neither as a mere copy of the European model nor as a complete departure. Rather, the Bengali sonnet must be understood in terms of both similarity and difference when compared to the European practice. In fact, Dutt's experimentations are indicative of the ways in which genre interacts with multiple languages to create a more complex picture of translation. Dutt's literary sensibility, mediated by his awareness of many languages and the literatures in these languages which in turn paved the way for reconstructing the genres in Bengali.

${ }^{13}$ Meenakshi Mukherjee's seminal work, Twice Born Fiction: Themes and Techniques of the Indian Novel in English (1971) explores this aspect in the genre of the novel and its practitioners. 
While the 'translational' culture of nineteenth-century Calcutta may be credited for enabling the linguistic, literary, and cultural exchanges of this kind, Dutt's understanding that languages and literatures cannot be studied in isolation and that there is an organicity to the ways in which linguistic and literary traditions evolve cannot be overlooked. In making the conscious choices of reading and learning from different linguistic and cultural traditions Dutt's sonnets and his epic remind us of the agency of the reader as a creative artist. Thus, in Dutt, one witnesses a curious bringing together of linguistic, literary, and cultural traditions and a careful intermingling. In weaving this rich and textured fabric, a palimpsest of sorts, Dutt was not only relying on his readings of the European, English, and Indian classics, he was also weaving in the contemporary socio-cultural and political history into his poetry.

In an interesting article on the several translations of Aeschylus's Agamemnon titled 'Seven Agamemnons', Reuben Brower (1966) claimed that a translation aspires to maintain anonymity and yet a contemporaneousness. This seems to be at the core of any understanding of cultural translation. Brower goes on to illustrate how in translating Aeschylus's Agamemnon, the translators from different ages were basically catering to what poetry meant in their age and time - the idea of what constitutes the poetic experience changes over time. In thus answering what is it to translate Aeschylus in the nineteenth or twentieth century, one needs to answer a rather basic question, what is poetry in the nineteenth or twentieth century? No translation would perhaps be relevant if it did not recognize its contemporaneousness. When Michael Madhusudan Dutt was translating the sonnet from the European models that he had sought inspiration from, he was also very much locating his creations in the contemporary discourse of poetry writing. Moreover, a rich tradition of 
poetry in Sanskrit and Bengali was already available to Dutt from which he would draw when composing his sonnets. The sonnet, an essentially European form, would in Dutt's experimentations, acquire a contemporary relevance and would eventually be indigenized. These multilingual traditions and their interactions would translate into the genres of the nineteenth-century Bengali epic and sonnet in Dutt's creations.

\section{Conclusion: Towards a Complex Lingual History in Translation}

Singha and Dutt help locate a translational history of nineteenth-century Calcutta - a history that tends to point towards the palimpsestic nature of multilingual practices and translations. These two representative writers provide an inkling of how varied and plural the methods of negotiations were at a time that was instrumental in the formation of identities and their assimilations. In juxtaposing Singha and Dutt, we get a glimpse into this complex texture of the nineteenth century. In most cases, these were re-articulations of experiences shared, lives lived and journeys undertaken. As we have seen in Dutt's case, his understanding of the Bengali language and its importance was mediated through his readings of the Greek, Latin, Hebrew, French, Italian, Tamil, Telugu, Sanskrit, and English languages and literature. It is a more productive exercise to view Dutt's translation of multiple works of literature and his literary creations in dialogue with each other - creations that can both be understood as translated and translating entities. This is also noticeable in many writers of the times who were engaged in a constant negotiation of the different linguistic domains that they inhabited. Living amidst various kinds of translations, these writers and creative artists were documenting their rapidly changing world and languages through their translations. The cultural encounter of the nineteenth century paved the way for new modes of 
Genres and Multilingual Contexts: The Translational Culture...

articulation, new genres, new ideologies, and new linguistic registers.

Not only does the nineteenth-century contest any claim to homogeneity, it also indicates the palimpsestic and translational culture of nineteenth-century Calcutta. Translation becomes a witness to and a carrier of transformations and rearticulation that the society undergoes. It seems to me that one will therefore need to rethink the nature and utility of translation and multilingualism, as illustrated in the writers above to understand the organicity of languages in nineteenth-century literary experimentations.

The present article explored the possibilities of revisiting nineteenth-century Calcutta through the lens of translation. The palimpsestic interconnections of linguistic, literary, and generic translations are indicative of a translational culture of the nineteenth century. As a translational city, nineteenthcentury Calcutta witnessed and facilitated movements across languages, between linguistic registers, works of literature, and genres to enable new mobilities and identities. The present article contributes to facilitating one such reading focusing on the role of languages and genres and the mediating space created by translations.

\section{References}

Brower, Reuben. A. (ed.). 1966. On Translation. New York: Oxford University Press.

Chakravorty, Swapan. 2004. 'Purity and Print: A Note on Nineteenth Century Bengali Prose'. In Abhijit Gupta \& Swapan Chakravorty (ed.), Print Areas: Book History in India. 197-226. New Delhi: Permanent Black.

DAS, SISIR KUMAR. 1991. A History of Indian Literature 18001910: Western Impact: Indian Response. Delhi: SahityaAkademi. 
DAS, SISIR KUMAR. 1978. Sahibs and Munshis: An Account of the College of Fort William. Calcutta: Orion Publications.

GENTZLER, EDWIN. 2017. Translation and Rewriting in the Age of Post-Translation Studies. New York: Routledge.

Ghosh, Anindita. 2006. Power in Print: Popular Publishing and the Politics of Language and Culture in a Colonial Society, 1778-1905. New York: Oxford University Press.

GuPTA, KshETRA. (ed.). 1965. Madhusudan Rachanabali (collected works of Michael Madhusudan Dutt). Calcutta: Sahitya Samsad.

JoshI, PRIYA. 2002. In Another Country: Colonialism, Culture and the Novel in India. New York: Columbia University Press.

LAHIRI, ASHISH. 2013. Caught Between Two Cultures: Science in Nineteenth Century Bengal. Kolkata: Thema.

MukHERJee, MeEnaKshi. 1971. Twice Born Fiction: Themes and Techniques of the Indian Novel in English. New Delhi: Heinemann.

MuRSHID, GolAM. 1992. Kalantare Bangla Gadya. Kolkata: Ananda Publishers.

Murshid, Golam. 1995. AsharChalaneBhuli (Biography of Madhusudan Dutt). Calcutta: Ananda Publishers Pvt.Ltd.

NiRANJANA, TEJASWINI. 1992. Siting Translation: History,

Post-Structuralism and the Colonial Context. Berkley: University of California Press.

RAdicE, WiLliam. (trans). 2010. The Poem of the Killing of Meghnad: MeghnadbadhKabya. New Delhi: Penguin Books.

SARKAR, SUMIT. 1998. Writing Social History. Delhi: Oxford University Press.

SimON, SHERRY. 2012. Cities in Translation: Intersections of Language and Memory. London and New York: Routledge. 
Genres and Multilingual Contexts: The Translational Culture...

SingHA, KalipRAsSANA. 2008. The Observant Owl Hootum's Vignettes of Nineteenth-century Calcutta. (Swarup Roy, Trans.). New Delhi: Permanent Black.

SPIVAK, GAYATRI. 2000. The Politics of Translation. In

Lawrence Venuti (ed.), The Translation Studies Reader. 397-416. New York and London: Routledge.

Venuti, LAWRENCE (ed.). 2000. The Translation Studies

Reader. New York and London: Routledge.

Viswanathan, Gauri. 1989. Masks of Conquest: Literary

Study and the British Rule in India. New York: Columbia University Press.s, 1989.

\section{Cite This Work:}

Chatterjee, Chandrani. 2021. Genres and Multilingual Contexts: The Translational Culture of Nineteenth-Century Calcutta. Translation Today, Vol. 15(1). 29-53.

DOI:10.46623/tt/2021.15.1.ar2 